\title{
An Exploration of Theoretical and Experimental Electron Density Distributions and SiO Bonded Interactions for the Silica Polymorph Coesite
}

\author{
G. V. Gibbs, $* \dagger$ Andrew E. Whitten, $\$$ Mark A. Spackman, $\$$ Marilena Stimpfl, $\$$ \\ Robert T. Downs, ${ }^{\S}$ and Michael D. Carducci" \\ The Department of Geosciences, Virginia Tech, Blacksburg, Virginia 24061, Chemistry Department, School of \\ Biomedical, Biological and Molecular Sciences, University of New England, Armidale, NSW 2351, Australia, \\ Departments of Geosciences and Chemistry, The University of Arizona, Tucson, Arizona 85721
}

Received: May 8, 2003; In Final Form: September 3, 2003

\begin{abstract}
A multipole representation of the experimental electron density distribution for the high-pressure silica polymorph coesite, using Hirshfeld-type radial functions, has been generated with single-crystal X-ray diffraction data recorded to a $\sin \theta_{\max } / \lambda$ value of $1.21 \AA^{-1}$ at $100 \mathrm{~K}$. Unlike an earlier modeling of the distribution, where a more limited data set was analyzed, deformation electron density maps display bananashaped isosurfaces in the lone-pair regions of each of the oxide anions involved in the bent SiOSi angles as well as teardrop-shaped ones along each of the $\mathrm{SiO}$ bond vectors. They also display a ring torus isosurface about $\mathrm{O}$, the oxide anion involved in the straight angle. Laplacian $-\nabla^{2} \rho$ maps display belt-shaped isosurfaces, centered near the apexes of the bent angles, that wrap about halfway around the oxide anions, with a ring torus-shaped isosurface surrounding O1. An analysis of $-\nabla^{2} \rho$ revealed that the $(3,-3)$ critical point associated with the anions involved in the bent angles are associated in general with larger maxima than that associated with the straight angle, evidence that the electron density is more locally concentrated on the oxide anions involved in the bent angles. As such, these anions are asserted to be more susceptible to electrophilic attack by hydrogen, a feature that provides an experimental basis for why hydrogen in $\mathrm{H}$ - and Al-bearing coesite avoids $\mathrm{O} 1$ and is observed to dock in the vicinity of the oxide anions involved in the bent angles. The bond critical point properties of the experimental multipole representation of the electron density distribution for coesite together with those for the very high-pressure silica polymorph, stishovite, conform with those calculated for the $\mathrm{SiO}$ bonded interactions for a relatively large number of silicate crystals. Not only are they similar in value with the theoretical properties, but together they correlate with the observed $\mathrm{SiO}$ bond lengths as predicted by the calculations. The observed $\mathrm{SiO}$ bonds display a relatively wide range of $\nabla^{2} \rho\left(r_{\mathrm{c}}\right)$ values between $\sim 10$ e $\AA^{-5}$ for stishovite and $\sim 20$ e $\AA^{-5}$ for coesite. The larger $\nabla^{2} \rho\left(r_{c}\right)$ values recorded for coesite, considered typical of first row closed-shell ionically bonded atoms, may not be typical for a closed-shell bonded interaction involving second row atoms such as the four-coordinate $\mathrm{Si}$ in coesite. The maxima along the bond vectors and in the lone-pair regions displayed by the experimental $\Delta \rho$ and $-\nabla^{2} \rho$ maps are indicative of shared covalent bonded interactions. The evidence suggests that the value of the electron density at the bond critical point for a given bonded interaction is a reliable measure of bond type: the larger the value $\rho\left(r_{\mathrm{c}}\right)$, the greater the shared covalent interaction.
\end{abstract}

\section{Introduction}

Experimental and theoretical studies of the silica polymorphs have been a meeting place where experiment has engaged theory in advancing our understanding of silica, its physical behavior, crystal chemistry and $\mathrm{SiO}$ bonded interactions. ${ }^{1,2}$ Not only have the studies provided a basis for understanding why there are so many different stable and metastable forms of silica but also why silica has such excellent glass forming properties. ${ }^{3,4}$ They have also provided an underpinning for the proposal that the structure of silica is governed in large part by short-ranged molecular-like binding forces. ${ }^{5-7}$ A connection has also been established between the $\mathrm{SiO}$ bond lengths, $R(\mathrm{SiO})$, and the bond critical point properties ${ }^{8}$ for theoretical electron density distributions, $\rho$, for molecular moieties of the silica polymorphs. ${ }^{9}$ The

\footnotetext{
$\dagger$ Virginia Tech.

$\doteqdot$ University of New England.

$\S$ Department of Geosciences, The University of Arizona.

" Department of Chemistry, The University of Arizona.
}

calculations show that the bond lengths decrease linearly as the theoretical value of the electron density at the bond critical point, $\rho\left(r_{\mathrm{c}}\right)$, increases together with a concomitant increase in the curvatures of the electron density at the point both perpendicular and parallel to the bond path. A mapping of the theoretical $\Delta \rho$ deformation density, the electron localization function, ELF, and the Laplacian $-\nabla^{2} \rho$ distributions for the silica polymorphs quartz, coesite, and stishovite, have also served to highlight sites of potential chemical reactivity and favorable docking sites for hydrogen ${ }^{10-12}$ in the lone-pair regions of the oxide anions.

Together with the theoretical advances, experimental static $\Delta \rho$ maps generated in a multipole refinement of the coesite structure display bonding maxima along each of the $\mathrm{SiO}$ bond vectors in the vicinity of the more electronegative oxide anions together with a low-lying bridge of density in the interior of each bent SiOSi angle. ${ }^{13}$ As asserted by Coppens, ${ }^{14}$ maxima along bond vectors is evidence for a shared covalent bonded interaction. On this basis it was concluded ${ }^{15}$ earlier that the $\mathrm{SiO}$

\subsection{1/jp030583+ CCC: \$25.00 @ xxxx American Chemical Society} Published on Web 00/00/0000 PAGE EST: 10.2 
bond in coesite and related silica polymorphs is predominantly covalent in character. In sharp contrast, it was asserted by Cohen ${ }^{16}$ that the maxima displayed along the bond vectors of quartz show that bonded interactions in silica are predominantly closed-shell ionic, consisting of "nearly fully charged $\mathrm{Si}^{4+}$ and $\mathrm{O}^{2-}$ ions rather than as neutral atoms with covalent bonds." However, conspicuously lacking in the experimental maps for coesite $^{13}$ are covalent features in the nonbonding regions of each of the oxide anions that can be ascribed to lone-pair electron density. With the exception of these missing features, maps calculated for representative hydroxyacid molecules with SiOSi dimers were found to be in close correspondence with static $\Delta \rho$ maps those observed for coesite. ${ }^{13}$ Despite the relatively small sizes of the molecules, the $\mathrm{SiO}$ bond lengths and SiOSi angles of the molecules likewise show a close correspondence with those observed for coesite and several other silica polymorphs. ${ }^{4,5}$ The $\Delta \rho$ maps for the molecules display welldeveloped maxima in both the bonding and nonbonding regions of the molecule. The close correspondence in the geometry and the electron density distributions generated for hydroxyacid silicate molecules and representative units in the silica polymorphs has been taken as evidence that the atomic interactions comprising the structure of coesite are quite similar to those of chemically and structurally similar molecules. ${ }^{4-6}$

In an experimental determination of the bond critical point, bcp, properties for coesite, ${ }^{17}$ it was found that the properties display a relatively wide range of values despite the small $\sim 2 \%$ range in the observed bond lengths. For example, the value of $\rho\left(r_{\mathrm{c}}\right)$, its curvatures, $\left|\lambda_{1}\right|$ and $\left|\lambda_{2}\right|$, perpendicular to the bond path and the Laplacian, $\nabla^{2} \rho\left(r_{\mathrm{c}}\right)$, each vary by $\sim 20 \%$ whereas the curvature of $\rho\left(r_{\mathrm{c}}\right)$ parallel to the path, $\lambda_{3}$, varies by only $\sim 10 \%$. The bcp properties were also found to be independent of the observed $\mathrm{SiO}$ bond lengths whereas the properties calculated for $\mathrm{H}_{12} \mathrm{Si}_{5} \mathrm{O}_{16}$ moieties of the structure vary, as observed above, in a regular way with bond length. ${ }^{9}$ In a theoretical study, ${ }^{18}$ the coesite structure was geometry optimized at zero pressure and at several pressures up to $17.4 \mathrm{GPa}$ and the bond critical point properties were determined. The nonequivalent $\mathrm{SiO}$ bond lengths and the $\mathrm{OSiO}$ and $\mathrm{SiOSi}$ angles of the structures were found to agree within $\sim 1 \%$ of those observed up to pressures of $5 \mathrm{GPa}$. In agreement with the molecular orbital calculations, the $\mathrm{SiO}$ bond lengths were found to be inversely correlated with the value of $\rho\left(r_{\mathrm{c}}\right)$, the curvatures of $\rho\left(r_{\mathrm{c}}\right)$ and $\nabla^{2} \rho\left(r_{\mathrm{c}}\right)$. Although the bcp properties for the model structure agree with those observed $^{17}$ to within $5-10 \%$, on average, they show a smaller range of values. Further, the ellipticity ${ }^{8}$ of the bond was found to decrease with increasing $\mathrm{SiOSi}$ angle with the bond becoming circular in cross section ${ }^{7,13}$ at $180^{\circ}$, a property, as we shall see later, that is related to features in the observed $\Delta \rho$ and $-\nabla^{2} \rho$ electron density distributions. As both the observed and calculated $\nabla^{2} \rho\left(r_{\mathrm{c}}\right)$ values for the $\mathrm{SiO}$ bonds in coesite ${ }^{17,18}$ are large, $\sim 23 \mathrm{e} \AA^{-5}$, and as $\left|\lambda_{1}\right| / \lambda_{2} \sim 0.18$, the bonds necessarily classify, according to the Bader and Essën rules, ${ }^{19}$ as closedshell ionic bonded interactions. However, Downs ${ }^{17}$ has argued that the bond is more intermediate in character given that its $\rho\left(r_{\mathrm{c}}\right)$ value is substantially larger $\left(\sim 1.05 \mathrm{e} \AA^{-3}\right)$ than that observed for the predominantly ionic $\mathrm{CaO}$ bond, $\sim 0.15 \mathrm{e}^{-3}$, in danburite, ${ }^{20} \mathrm{CaB}_{2} \mathrm{Si}_{2} \mathrm{O}_{8}$.

\section{Statement of Problem}

It is apparent that the bcp properties calculated for both coesite and representative moieties display systematic and welldeveloped trends when plotted against $R(\mathrm{SiO})$. Although the values obtained in these calculations agree fairly well with those observed, the experimental properties fail to correlate ${ }^{17}$ with $R(\mathrm{SiO})$. It can be argued that this problem is related in part to the limited number of diffraction data used in the multipole refinement of the structure. ${ }^{17}$ The absence of the maxima in the $\Delta \rho$ maps in the lone-pair regions can accordingly be ascribed to the lack of high-angle data. Furthermore, the earlier refinements ${ }^{13,17}$ were incomplete given the intractability and bias of the radial functions used in the multipole modeling of the electron density distribution. ${ }^{21,22}$ As observed above, the absence of the trend between $R(\mathrm{SiO})$ and the bond critical point properties can be arguably due to the small range of the observed bond lengths. In the case of the very high-pressure silica polymorph stishovite where the $\mathrm{SiO}$ bond lengths show twice the range of values as observed for coesite, the experimental bcp properties were observed ${ }^{23}$ to correlate with $R(\mathrm{SiO})$. It was also found that the properties of stishovite agree with those generated for a variety of geometry optimized hydroxyacid silicate molecules both qualitatively and quantitatively. ${ }^{23,24}$ Further, the evidence ${ }^{23}$ indicates that the closed-shell nature of the bond increases with increasing $R(\mathrm{SiO})$ and decreasing $\rho\left(r_{\mathrm{c}}\right)$ and $\nabla^{2} \rho\left(r_{\mathrm{c}}\right)$.

To circumvent the problem of a limited data set, a relatively large set of single-crystal X-ray diffraction data was collected for this study and used to obtain a multipole representation of the experimental electron density distribution for coesite (1) to determine whether the features in $\Delta \rho$ and $-\nabla^{2} \rho$ maps in the bonding and lone-pair regions of the crystal conform with those generated by theory, (2) to explore the extent to which the bcp properties of the distribution agree with those generated by theoretical calculations, and (3) to relate the properties of the $\mathrm{SiO}$ bond to its elusive character ${ }^{7}$ and bond length variations.

Coesite is an ideal material for studying $\mathrm{SiO}$ bonded interactions. It is centrosymmetric, consisting of two nonequivalent $\mathrm{SiO}_{4}$ silicate tetrahedra that share corners in forming a dense framework structure. It contains eight nonequivalent $\mathrm{SiO}$ bond lengths that range between 1.596 and $1.622 \AA$, twelve nonequivalent $\mathrm{OSiO}$ angles that range between $108.0^{\circ}$ and $110.5^{\circ}$ and five nonequivalent $\mathrm{SiOSi}$ angles that range between $136.7^{\circ}$ and $180.0^{\circ}$. Although the bond lengths in coesite are restricted to a small range of values, $R(\mathrm{SiO})$ correlates with the $\mathrm{SiOSi}$ angle, as observed above, with the shorter bonds involving wider angles, as predicted by theoretical calculations. ${ }^{7,18,25}$ It will also be of interest to compare the properties of $\rho\left(r_{\mathrm{c}}\right)$ with those observed for stishovite. ${ }^{23}$ Finally, it is anticipated that the study will not only advance our understanding of the $\mathrm{SiO}$ bonded interaction but also provide an experimental basis for understanding why hydrogen adopts the positions that it does in $\mathrm{H}$ and Al-bearing coesite and stishovite crystals synthesized and formed at high temperature and pressures. ${ }^{10,11,26,27}$

\section{Experimental Procedure and Details}

The coesite crystals used for this study, ${ }^{25}$ synthesized from powdered amorphous anhydrous silica at $4.5 \mathrm{GPa}$ and $650{ }^{\circ} \mathrm{C}$, were kindly supplied by Dr. Charles T. Prewitt of the Carnegie Institute of Washington, D.C. One displaying sharp extinction under the polarizing microscope was selected and was found to be highly diffracting, yielding very sharp peaks with an average width of $\sim 0.1^{\circ}$. Prior to data collection, the crystal was ground to a sphere $\sim 100 \mu \mathrm{m}$ in diameter to minimize the absorption of the X-ray beam and to simplify the modeling of the absorption correction.

Single-crystal X-ray diffraction intensity data were recorded at $100 \mathrm{~K}$ with a Bruker SMART1000 diffractometer equipped with a CCD area detector, using graphite-monochromated Mo 
$\mathrm{K} \alpha(\lambda=0.71073 \AA)$ radiation. More than 14690 frames were collected between 0 and $120^{\circ} 2 \theta\left(\sin \theta_{\text {max }} / \lambda=1.21 \AA^{-1}\right)$, using the Bruker SMART software package. ${ }^{28}$ Each frame was recorded as an $\omega$ scan of $0.15^{\circ}$ with a 10 s run time exposure with the detector set at $0^{\circ}$ and $30 \mathrm{~s}$ for the other detector positions. Short runs of 50 frames each were periodically recorded to monitor the stability of the X-ray beam. The CCD area detector entry was positioned in the experiment at a distance of $40 \mathrm{~mm}$ from the crystal to cover a section of $\sim 60^{\circ}$ in $2 \theta$.

Upon completion of the data collection, the Bruker SAINT software was used to integrate the observed intensities. The starting dimensions of the box were $X=1.1^{\circ}, Y=1.1^{\circ}$, and $Z$ $=0.4^{\circ}$; however, the size of the box used to integrate the intensities was optimized and a narrow frame algorithm was adopted as a integration condition due to the sharpness of the peaks. Further, to monitor crystal displacements (none was detected), the orientation matrix was updated periodically every 303 frames; no symmetry constraints were imposed on the matrix. For all runs, the dimensions of the box converged to the optimized values. The Lp corrections were applied to the intensities using SAINT of the SMART CCD package.

A total of 18071 intensities was observed and used to generate two $F_{\mathrm{o}}{ }^{2}$ data sets: one contained all of the 18071 unmerged $F_{\mathrm{o}}{ }^{2}$ 's (highest and lowest redundancy of 11.05 and 4.39 , respectively) and the other contained only the nonequivalent intensities. The second set was generated by averaging the equivalent ${F_{\mathrm{o}}}^{2}$ 's for Laue point group type $2 / m$, using the program SORTAV. ${ }^{29}$ Systematic absences were eliminated from the data set using the limiting diffraction conditions for space group type $C 2 / c$. In this process, a total of 4018 nonequivalent $F_{\mathrm{o}}{ }^{2}$ 's was generated. The observed $F_{\mathrm{o}}{ }^{2}$ 's for both data sets were corrected for absorption using the program SADABS. ${ }^{30} \mathrm{~A}$ regression analysis completed for 6067 observed $d$ spacing generated the following cell dimensions: $a=7.1325(1) \AA, b$ $=12.3712(2) \AA, c=7.1763(1) \AA$, and $\beta=120.364(1)^{\circ}$ with the esds given in the parentheses.

\section{Multipole Analyses}

Our first attempt at a multipole refinement, using the 4018 merged data, was based on a conventional multipole model. This included density-localized monopole radial functions, as well as single-exponential radial functions, $r^{n} \exp (-\alpha r)$, for higher multipoles up to and including the hexadecapole level on both $\mathrm{Si}$ and $\mathrm{O}$. For $\mathrm{Si}, n=4$ for all higher multipoles and for $\mathrm{O}, n=2,2,4$, 4, for dipoles through hexadecapoles, respectively. Along with all multipoles, a $\kappa$ scaling parameter was refined separately for the $\mathrm{Si}$ and $\mathrm{O}$ valence monopoles as well as a single radial exponent for all $\mathrm{Si}$ atoms and a separate exponent for all $\mathrm{O}$ atoms. The resulting model static deformation density maps (i.e., deconvoluted from thermal motion) were found to yield the expected maxima along each of the $\mathrm{SiO}$ vectors and in the nonbonding regions of the oxide anions. However, the maps were also found to display a spurious ring

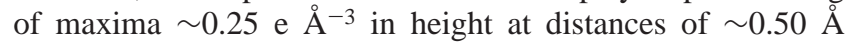
surrounding each $\mathrm{Si}$ atom. The cause of this feature was isolated to the unusually large value of $\kappa$ obtained in the refinement of the $\mathrm{Si}$ valence monopole. Whereas $\kappa(\mathrm{O})$ was found to be quite sensible at 0.97 , the $\kappa(\mathrm{Si})$ refined to a value of 1.43 , suggesting a very large contraction of the $\mathrm{Si}$ atom valence monopole.

A useful model study, ${ }^{21}$ undertaken for a number of diatomic molecules, demonstrates that monopole deformations, deduced from Hartree-Fock wave functions, can be fitted extremely well with $\kappa$-refined valence monopole functions. Typically, the $\kappa$ values were found to be much less than 1.25 and close to 1.0.
Apropos to the present study of coesite, it was found ${ }^{21}$ that $\kappa(\mathrm{Si})=0.990$ for $\mathrm{SiH}$ and 1.001 for $\mathrm{SiO}$ and $\kappa(\mathrm{O})=0.987$ for $\mathrm{OH}$ and 0.971 for $\mathrm{SiO}$. These results provide strong evidence that the value of $\kappa(\mathrm{Si})=1.43$, obtained in the initial multipole refinement, is unrealistically large and most likely not a reflection of a real electronic effect. This suggests that the experimental data are lacking the information content necessary to determine a meaningful value for $\kappa(\mathrm{Si})$. To explore one possible reason for this problem, a plot of $|\Delta F|=\left|F_{\mathrm{o}}\right|-\left|F_{\mathrm{c}}\right|$ against $\sin \theta / \lambda$ was found to reveal a large number of discrepancies at relatively high $\sin \theta / \lambda$ values. Imposing a $3 \sigma$ cutoff on $\left|F_{\mathrm{o}}\right|$ removed the majority of these discrepancies, but a subsequent multipole refinement against the data subject to this $3 \sigma$ cutoff yielded no changes in the refined values of $\kappa(\mathrm{Si})$ and $\kappa(\mathrm{O})$. It was concluded that $\kappa(\mathrm{Si})$ cannot be determined reliably from the experimental data set despite its large size.

To overcome this problem, a set of theoretical structure factors was calculated for coesite and subjected to the same refinement strategy. The CRYSTAL98 code, ${ }^{31}$ denoted here as C98, was used together with the atomic coordinates of the geometry optimized structure generated for coesite ${ }^{18}$ and the $(9 \mathrm{~s} 5 \mathrm{p}) /[4 \mathrm{~s} 2 \mathrm{p}]$ contracted double- $\zeta$ contracted Gaussian type basis sets ${ }^{32}$ for $O$ together with the $(12 s 8 p) /[6 s 4 p]$ contracted double- $\zeta$ basis $\mathrm{set}^{33}$ for $\mathrm{Si}$. The basis sets for both $\mathrm{Si}$ and $\mathrm{O}$ were augmented with single d-type polarization functions with exponents of 0.85 au for $\mathrm{O}$ and 0.5 au for Si. To obtain convergence in the Hartree-Fock calculations, it was necessary to remove the diffuse p-type function on Si. From the resulting Hartree-Fock model electron density distribution, a complete set of structure factors was generated for coesite to a resolution of $\sin \theta_{\max } / \lambda$ $=1.21 \AA^{-1}$. A multipole modeling of these theoretical data is ideal for several reasons: (1) the scale factor is exactly known, (2) the data set is free from thermal motion, (3) no corrections for systematic effects (i.e., extinction, absorption, and anomalous dispersion) are required, and (4) there are no experimental errors. Despite the ideal set of structure factors, the refinement resulted in a $R$ factor of $0.21 \%$, suggesting that the multipole refinement remained deficient in its ability to model every aspect of the electron density distribution.

To see how well the chosen multipole model represents the actual electron density distribution, the model deformation electron density distribution resulting from the multipole fitting of this set of theoretical structure factors was compared critically with the deformation density calculated directly from the Hartree-Fock electron density distribution for the crystal. Although the maxima associated with the $\mathrm{SiO}$ bond vectors are well-reproduced, it was immediately apparent that the sharper maxima in the lone-pair regions (i.e., outside and inside the $\mathrm{SiOSi}$ angle) were very poorly fit. There are two possible causes for this deficiency: (1) the lack of flexibility and bias afforded by the single-exponent radial functions and (2) the limited resolution of the computed data set.

The effect of the resolution of the data was examined by generating sets of theoretical structure factors for given sets of $\sin \theta_{\max } / \lambda$ values and computing deformation electron density maps, $\Delta \rho^{\text {Fourier }}$, via Fourier summations $F_{\text {C98 }}^{\text {Fourier }}-F_{\text {IAM. }}$ Figure 1 illustrates the results of these calculations obtained using this approach for the $\mathrm{Si} 2 \mathrm{O} 2 \mathrm{Si} 2$ plane in coesite for structure factors calculated for the six following $\sin \theta_{\max } / \lambda$ values: $0.8,0.9,1.2$, $1.5,1.8$, and $2.0 \AA^{-1}$. The figure makes it abundantly clear that the fine details of the sharper deformations around the oxide anions are not revealed even for the current experimental data set; with a resolution of $\sin \theta_{\max } / \lambda=1.21 \AA^{-1}$ (which is unusually high), the data effectively lacks this information. It 


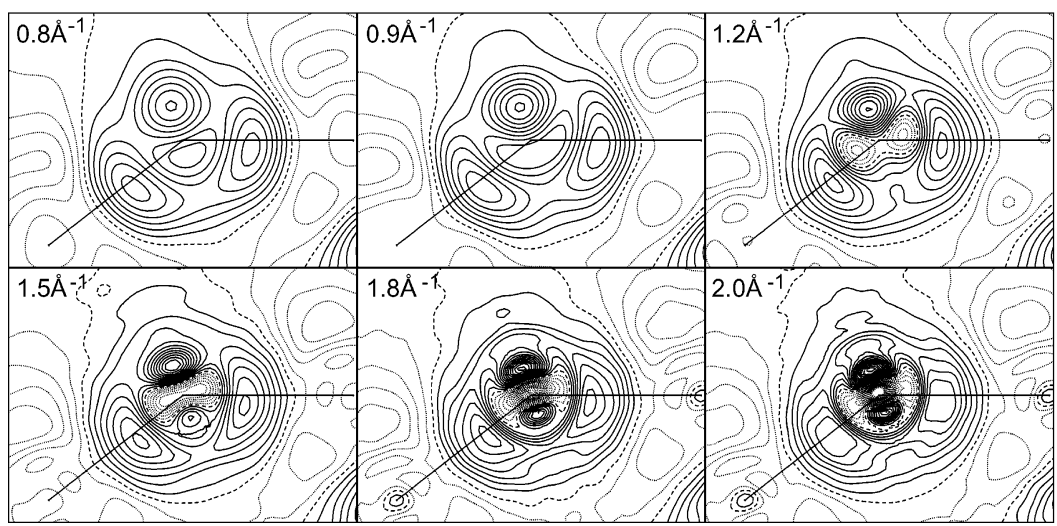

Figure 1. Deformation maps calculated for the Si2O2Si2 angle with amplitudes $F(h k l)_{\mathrm{C} 98}-F(h k l)_{\text {IAM }}$ with VALRAY ${ }^{35}$ for sin $\theta_{\max } / \lambda$ values of $0.8,0.9,1.2$ (top row, left to right) and $1.5,1.8,2.0 \AA^{-1}$ (bottom row, left to right). $F(h k l)_{\mathrm{C} 98}$ are structure factors calculated with CRYSTAL98 ${ }^{31}$ for the electron density distribution of the geometry optimized structure of coesite, ${ }^{18}$ and $F(h k l)_{\text {IAM }}$ are structure factors calculated for the procrystal representation of the electron density distribution. The contour line interval is $0.05 \mathrm{e} \AA^{-3}$ with positive contours solid, negative ones dotted, and the zero contour dashed.

is only with a resolution near $1.5 \AA^{-1}$ that these features become reasonably well-defined in shape and magnitude. It is noteworthy that at a resolution of $0.9 \AA^{-1}$, as in the case of the earlier data set, ${ }^{13}$ virtually no covalent lone-pair features were resolved near the oxide anions.

A comparison of the theoretical deformation Fourier map at the $1.21 \AA^{-1}$ resolution (Figure 1) with the static model of electron density derived from the standard multipole model and applied to the same theoretical data, suggested that it should be possible to fit the lone-pair type features with a sufficiently flexible multipole model. It has previously been observed repeatedly in recent electron density studies (cf. ref 22) that the usual single-exponential radial functions are inadequate for our purposes and a two-term function can provide a significant improvement in a refinement. Hirshfeld's original multipole refinement model, embodied in the FEXP code, ${ }^{34}$ includes twoterm radial functions for dipole and quadrupole multipoles and, although not commonly used these days, it has previously been shown to be essential to provide an adequate fit to the deformation density on the oxide anion in corundum. ${ }^{21}$ For these reasons, the present multipole refinement on coesite was augmented with extra radial functions added to the dipole and quadrupole sets on the oxide anion. These extra functions shared the same exponent as the first set but with $n=4$ in both cases. A subsequent multipole refinement with the theoretical data resulted $\kappa$ values of 0.91 on $\mathrm{Si}$ and 0.97 on $\mathrm{O}$, resulting in good agreement with the values obtained for several diatomic molecules; ${ }^{21}$ exponents for the radial functions converged at values of $\alpha(\mathrm{Si})=2.25 \mathrm{au}^{-1}$ and $\alpha(\mathrm{O})=5.18 \mathrm{au}^{-1}$. In the final multipole refinement of the experimental data, the same additional dipole and quadrupole radial functions were added to the $\mathrm{O}$ atoms and a data cutoff of $F^{2}>3 \sigma\left(F^{2}\right)$ was chosen. In addition, $\kappa(\mathrm{Si})$ was fixed at 0.91 for both $\mathrm{Si}$ atoms and the radial exponents for the higher multipoles were fixed at the values obtained in the fit to the theoretical structure factors. Monopole populations were constrained to yield a neutral unit cell. As the extinction in the data was very small, it was modeled with an isotropic extinction correction (type 1, Gaussian mosaic). The refinement converged with $R_{\mathrm{w}}=2.00 \%, R(F)=2.24 \%$, and a goodness of fit of 1.33.

The maximum extinction encountered in the refinement was $1.8 \%$ for the $F(040)$ reflection. The $\kappa$ parameter for the $\mathrm{O}$ atoms converged to a value of $\kappa(\mathrm{O})=0.992(2)$ and the atomic charges obtained by summing over the monopole populations on each atom type were found to differ little from neutrality, $q(\mathrm{Si})=$ $+0.16(6)$ and $q(\mathrm{O})=-0.08(4)$. Positional and thermal param-
TABLE 1: Atomic Coordinates ${ }^{a}$ and Vibrational Parameters $^{b}$

\begin{tabular}{llllllll}
\hline & \multicolumn{1}{c}{$\mathrm{Si} 1$} & \multicolumn{1}{c}{$\mathrm{Si} 2$} & \multicolumn{1}{c}{$\mathrm{O} 1$} & \multicolumn{1}{c}{$\mathrm{O} 2$} & \multicolumn{1}{c}{$\mathrm{O} 3$} & $\mathrm{O} 4$ & \multicolumn{1}{c}{ O5 } \\
\hline$x$ & 0.14001 & 0.50725 & 0 & $1 / 2$ & 0.26453 & 0.31262 & 0.01843 \\
$y$ & 0.10856 & 0.15794 & 0 & 0.11548 & 0.12428 & 0.10340 & 0.21178 \\
$z$ & 0.07220 & 0.54138 & 0 & $3 / 4$ & 0.93864 & 0.32769 & 0.47672 \\
$U_{11}, \AA^{2}$ & 0.0027 & 0.0028 & 0.0048 & 0.0053 & 0.0044 & 0.0051 & 0.0048 \\
$U_{22}, \AA^{2}$ & 0.0024 & 0.0026 & 0.0034 & 0.0049 & 0.0059 & 0.0054 & 0.0031 \\
$U_{33}, \AA^{2}$ & 0.0026 & 0.0022 & 0.0053 & 0.0033 & 0.0051 & 0.0030 & 0.0060 \\
$-U_{12}, \AA^{2}$ & 0.0004 & 0.0002 & 0.0013 & 0 & 0.0008 & 0.0010 & 0.0005 \\
$U_{13}, \AA^{2}$ & 0.0013 & 0.0013 & 0.0022 & 0.0029 & 0.0032 & 0.0009 & 0.0029 \\
$-U_{23}, \AA^{2}$ & 0.0003 & 0.0001 & 0.0005 & 0 & 0.0003 & 0.0007 & 0.0003 \\
$B_{\text {eq }}, \AA^{2}$ & 0.202 & 0.202 & 0.370 & 0.331 & 0.378 & 0.392 & 0.360
\end{tabular}

${ }^{a}$ Given at the 0.00005 significance level. ${ }^{b}$ Given at the at the 0.0005 $\AA^{2}$ significance level.

TABLE 2: Bond Lengths $(\AA),{ }^{a}$ Angles (deg), ${ }^{b}$ and Selected Distances $(\AA)$

\begin{tabular}{|c|c|c|c|c|c|}
\hline SilO1 & 1.596 & $\mathrm{Si} 2 \mathrm{O} 2$ & 1.612 & $\angle \mathrm{Si} 1 \mathrm{O} 1 \mathrm{Si} 1$ & 180.0 \\
\hline Si1O3 & 1.614 & $\mathrm{Si} 2 \mathrm{O} 3$ & 1.615 & $\angle \mathrm{Si} 2 \mathrm{O} 2 \mathrm{Si} 2$ & 142.0 \\
\hline SilO4 & 1.612 & $\mathrm{Si} 2 \mathrm{O} 4$ & 1.607 & $\angle \mathrm{Si} 1 \mathrm{O} 3 \mathrm{Si} 2$ & 144.2 \\
\hline Si1O5 & 1.622 & $\mathrm{Si} 2 \mathrm{O} 5$ & 1.620 & $\angle \mathrm{Si} 1 \mathrm{O} 4 \mathrm{Si} 2$ & $\begin{array}{l}149.7 \\
1367\end{array}$ \\
\hline$\angle \mathrm{O} 1 \mathrm{Si} 1 \mathrm{O} 3$ & 110.5 & $\angle \mathrm{O} 2 \mathrm{Si} 2 \mathrm{O} 3$ & 109.7 & Si1Si1 & 3.192 \\
\hline$\angle \mathrm{O} 1 \mathrm{Si} 1 \mathrm{O} 4$ & 109.2 & $\angle \mathrm{O} 2 \mathrm{Si} 2 \mathrm{O} 4$ & 109.4 & $\mathrm{Si} 2 \mathrm{Si} 2$ & 3.047 \\
\hline$\angle \mathrm{O} 1 \mathrm{Si} 1 \mathrm{O} 5$ & 109.8 & $\angle \mathrm{O} 2 \mathrm{Si} 2 \mathrm{O} 5$ & 110.1 & $\mathrm{Si} 1 \mathrm{Si} 2$ & 3.074 \\
\hline$\angle \mathrm{O} 3 \mathrm{Si} 1 \mathrm{O} 4$ & 110.3 & $\angle \mathrm{O} 3 \mathrm{Si} 2 \mathrm{O} 4$ & 108.8 & Si1Si2 & 3.108 \\
\hline$\angle \mathrm{O} 3 \mathrm{Si} 1 \mathrm{O} 5$ & 108.0 & $\angle \mathrm{O} 3 \mathrm{Si} 2 \mathrm{O} 5$ & 109.4 & $\mathrm{Si} 1 \mathrm{Si} 2$ & 3.013 \\
\hline$\angle \mathrm{O} 4 \mathrm{Si} 1 \mathrm{O} 5$ & 109.0 & $\angle \mathrm{O} 4 \mathrm{Si} 2 \mathrm{O} 5$ & 109.5 & & \\
\hline O1O3 & 2.638 & $\mathrm{O} 2 \mathrm{O} 3$ & 2.639 & & \\
\hline $\mathrm{O} 1 \mathrm{O} 4$ & 2.616 & $\mathrm{O} 2 \mathrm{O} 4$ & 2.626 & & \\
\hline O1O5 & 2.632 & $\mathrm{O} 2 \mathrm{O} 5$ & 2.648 & & \\
\hline $\mathrm{O} 3 \mathrm{O} 4$ & 2.647 & $\mathrm{O} 3 \mathrm{O} 4$ & 2.622 & & \\
\hline O3O5 & 2.619 & $\mathrm{O} 3 \mathrm{O} 5$ & 2.640 & & \\
\hline O4O5 & 2.634 & O4O5 & 2.634 & & \\
\hline
\end{tabular}

${ }^{a}$ Given at the $0.001 \AA$ significance level. ${ }^{b}$ Given at the $0.1^{\circ}$ significance level.

eters resulting from the multipole refinement are given in Table 1 , and the nonequivalent bond lengths, angles, and selected distances are given in Table 2. The bcp properties for the multipole representation for the observed electron density distribution, calculated with VALRAY, ${ }^{35}$ are given in Table 3. Static deformation density maps were generated and display maxima along each of the $\mathrm{SiO}$ vectors and in the lone-pair region of each oxide anion. However, unlike the earlier maps generated with a more limited data set, the spurious maxima about the $\mathrm{Si}$ atoms are absent. It is noteworthy that these maxima are displayed in $\mathrm{SiOSi} \Delta \rho$ distributions published by earlier workers. ${ }^{36}$ 
TABLE 3: Bond Critical Point Properties Experimental $\boldsymbol{F}(\boldsymbol{h k l})_{\text {obs }}$ Multipole Model Representation ${ }^{a}$ of $\boldsymbol{\rho}$

\begin{tabular}{|c|c|c|c|c|c|}
\hline bond & $R(\mathrm{SiO}), \AA$ & $\rho\left(r_{\mathrm{c}}\right), \mathrm{e} \AA^{-3}$ & $\lambda_{1,2}, \mathrm{e} \AA^{-5}$ & $\lambda_{3}, \mathrm{e} \AA^{-5}$ & $\nabla^{2} \rho\left(r_{\mathrm{c}}\right)$, e $\AA^{-5}$ \\
\hline Si1O1 & $1.596(1)$ & $1.02(1)$ & $-7.8(2)$ & $38.4(3)$ & $22.7(3)$ \\
\hline $\mathrm{Si} 2 \mathrm{O} 2$ & $1.612(1)$ & 1.01(1) & $-7.7(2)$ & $36.0(4)$ & $20.6(4)$ \\
\hline SilO3 & $1.614(2)$ & $1.04(1)$ & $-7.8(2)$ & $37.4(4)$ & $21.9(6)$ \\
\hline $\mathrm{Si} 2 \mathrm{O} 3$ & $1.616(1)$ & $1.00(1)$ & $-7.5(2)$ & $37.7(5)$ & $22.7(5)$ \\
\hline SilO4 & $1.613(4)$ & $1.00(2)$ & $-7.3(1)$ & $37.2(4)$ & $22.6(6)$ \\
\hline $\mathrm{Si} 2 \mathrm{O} 4$ & $1.607(4)$ & $0.96(2)$ & $-7.2(1)$ & $36.2(4)$ & $21.8(5)$ \\
\hline Si1O5 & $1.622(1)$ & $0.96(2)$ & $-7.8(2)$ & $34.9(5)$ & $19.4(5)$ \\
\hline $\mathrm{Si} 2 \mathrm{O} 5$ & $1.620(1)$ & $0.99(2)$ & $-7.2(2)$ & $35.3(5)$ & $21.0(5)$ \\
\hline \multicolumn{6}{|c|}{ Theoretical $F(h k l)_{\mathrm{C} 98}$ Multipole Model Representation of $\rho$} \\
\hline SilO1 & 1.592 & 1.01 & -7.8 & 38.6 & 23.0 \\
\hline $\mathrm{Si} 2 \mathrm{O} 2$ & 1.610 & 0.98 & -7.4 & 35.8 & 21.1 \\
\hline $\mathrm{Si} 1 \mathrm{O} 3$ & 1.614 & 0.98 & -7.3 & 35.1 & 20.4 \\
\hline $\mathrm{Si} 2 \mathrm{O} 3$ & 1.614 & 0.97 & -7.3 & 35.1 & 20.5 \\
\hline $\mathrm{Si1O} 4$ & 1.611 & 0.98 & -7.4 & 35.1 & 20.4 \\
\hline $\mathrm{Si} 2 \mathrm{O} 4$ & 1.605 & 0.99 & -7.4 & 36.5 & 21.6 \\
\hline Si1O5 & 1.621 & 0.96 & -7.2 & 34.2 & 19.8 \\
\hline $\mathrm{Si} 2 \mathrm{O} 5$ & 1.621 & 0.96 & -7.2 & 34.2 & 19.9 \\
\hline \multicolumn{6}{|c|}{ Theoretical $\rho$-Distribution for the Model Coesite Structure ${ }^{18}$} \\
\hline Si1O1 & 1.592 & 1.00 & -6.7 & 38.8 & 25.4 \\
\hline $\mathrm{Si} 2 \mathrm{O} 2$ & 1.610 & 0.98 & -6.4 & 36.4 & 23.5 \\
\hline $\mathrm{Si} 1 \mathrm{O} 3$ & 1.614 & 0.96 & -6.3 & 35.7 & 23.2 \\
\hline $\mathrm{Si} 2 \mathrm{O} 3$ & 1.614 & 0.97 & -6.3 & 35.7 & 23.2 \\
\hline $\mathrm{Si} 1 \mathrm{O} 4$ & 1.611 & 0.97 & -6.2 & 36.0 & 23.5 \\
\hline $\mathrm{Si} 2 \mathrm{O} 4$ & 1.605 & 0.98 & -6.4 & 37.0 & 24.1 \\
\hline Si1O5 & 1.621 & 0.96 & -6.2 & 34.9 & 22.5 \\
\hline $\mathrm{Si} 2 \mathrm{O} 5$ & 1.621 & 0.96 & -6.1 & 34.8 & 22.5 \\
\hline
\end{tabular}

${ }^{a}$ The esds are given in parentheses and refer to the digit quoted.

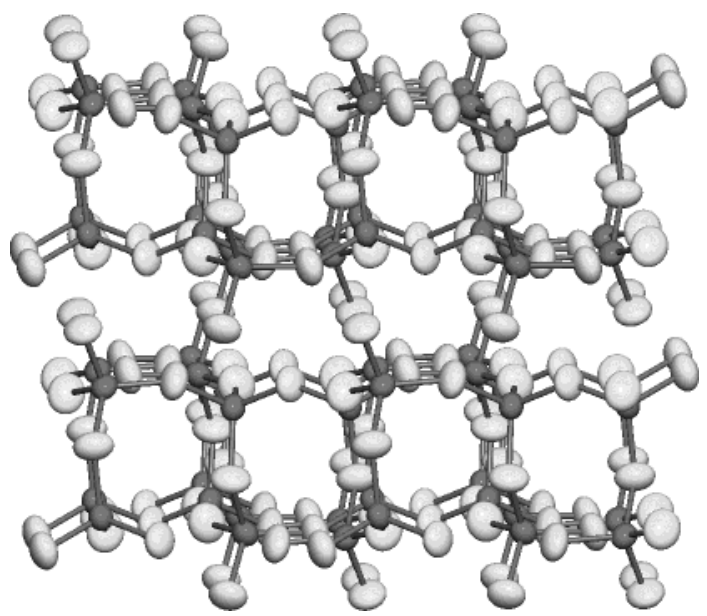

Figure 2. Drawing of the structure of coesite viewed down $\sim[100]$ displaying the $99.999 \%$ probability thermal ellipsoid isosurfaces for the $\mathrm{Si}$ and $\mathrm{O}$ atoms. The smaller isosurfaces represent the thermal ellipsoids for $\mathrm{Si}$, and the large ones represent those for O. [010] runs vertically and [001] runs horizontally in the drawing. The lines connecting adjacent atoms parallel the bond paths between $\mathrm{Si}$ and $\mathrm{O}$.

The equivalent isotropic temperature factors, $B_{\mathrm{eq}}=8 \pi^{2}\left\langle\sigma^{2}\right\rangle$ $\left(\left\langle\sigma^{2}\right\rangle\right.$ is the average mean square displacement $\left.{ }^{37}\right)$, for the Si and $\mathrm{O}$ atoms determined at $100 \mathrm{~K}$ are smaller (Table 1 ), by a factor of $\sim 2$, than those observed in an earlier room-temperature measurement. ${ }^{13}$ However, the orientations of the thermal ellipsoids are in close agreement with those determined at room temperature. ${ }^{13}$ The largest difference is $10^{\circ}$ with an average difference of $3^{\circ}$. As observed for the room-temperature data, the thermal ellipsoids are prolate uniaxial in shape (Figure 2) with the larger two root-mean-square amplitude displacements bisecting the SiOSi angles and the shorter ones oriented perpendicular to the bisector of the angles directed roughly in the directions of the $\mathrm{SiO}$ bond vectors. Also, the bond lengths and angles observed at $100 \mathrm{~K}$ are in excellent agreement with those generated in the first-principle calculations for a model structure of coesite. ${ }^{18}$ The observed $\mathrm{SiO}$ bond lengths are 0.0018 $\AA$ longer, on average, than those of the model structure, and the observed SiOSi angles are $0.3^{\circ}$ wider, on average, than those of the model structure. In addition, the $\mathrm{OSiO}$ angles agree within $0.2^{\circ}$, on average, with those of the model structure. Given that the model structure was generated at absolute zero with no zero point vibration, its shorter bond lengths are unexpected, as thermal motion results in a decrease in the apparent bond length.

\section{Deformation Density Distributions}

For purposes of comparison, three different sets of $\Delta \rho$ maps were generated for each of the five nonequivalent SiOSi angles in coesite (Figure 3): (1) theoretical $\Delta \rho_{\mathrm{C} 98}=\rho_{\mathrm{C} 98}-\rho_{\text {IAM }}$ deformation maps displayed in column 1 of Figure 3 ( $\rho_{\mathrm{C} 98}$ is the electron density distribution calculated for the observed structure of coesite with $\mathrm{C} 98^{31}$ and $\rho_{\mathrm{IAM}}$ is the relevant procrystal electron density distribution), (2) theoretical static deformation $\Delta \rho_{\mathrm{C} 98}^{\text {multipole }}=\rho_{\mathrm{C} 98}^{\text {multipole }}-\rho_{\text {IAM }}$ maps displayed in column 2 of Figure 3 (generated in a multipole refinements of $F(h k l)_{\mathrm{C} 98}$ where $F(h k l)_{\mathrm{C} 98}$ are the structure factors calculated from the $\rho_{\mathrm{C} 98}$ electron density for the model structure ${ }^{18}$ ), and (3) observed static $\Delta \rho_{\exp }^{\text {multipole }}=\rho_{\exp }^{\text {multipole }}-\rho_{\text {IAM }}$ deformation maps displayed in column 3 of Figure 3 (where $\rho_{\exp }^{\text {multipole }}$ was generated in a multipole refinement of $F_{\text {obs }}$ ).

Not only do the theoretical $\Delta \rho$ maps in Figure 3 display welldefined maxima along each of the $\mathrm{SiO}$ bond vectors and in the lone-pair regions, but the $\Delta \rho_{\exp }^{\text {multipole }}$ ones do as well. It is clear that the maxima in the lone-pair regions owe their existence to the more extensive data set collected in this study. In addition, the theoretical $\Delta \rho_{\mathrm{C} 98}$ maps (Figure 3, column 1) are strikingly similar to those calculated earlier for the $\mathrm{H}_{6} \mathrm{Si}_{2} \mathrm{O}_{7}$ molecule. ${ }^{13}$ The positions of the maxima for the bulk crystals are the same as those in the maps for the molecules, and the heights of the maxima are virtually the same as well. Also, low-lying bridges of electron density occur on the interior of each SiOSi angle as observed earlier. ${ }^{13}$ In each of the theoretical, and in several of the experimental maps, the maxima along the $\mathrm{SiO}$ bond vectors are displaced off the vectors toward the interior of the SiOSi angles, an effect that can be ascribed to repulsions between the localization of the electron density in the lone-pair and bondpair regions. Unlike the maps displayed in columns 2 amd 3, the $\Delta \rho_{\mathrm{C} 98}$ maps show maxima adjacent to the oxide anions inside the SiOSi angle that sharpen with decreasing angle. The $\Delta \rho_{\mathrm{C} 98}^{\text {multipole }}$ maps (Figure 3, column 2) for coesite are topologically similar to the $\Delta \rho_{\exp }^{\text {multipole }}$ maps (Figure 3, column 3), but there are differences in the shapes and the heights of the maxima. Overall, despite the limited resolution of the data used to generate the experimental maps, the systematic errors, the bias introduced by the limited flexibility of the radial functions in the multipole refinements, ${ }^{21,22}$ and the defects in the multipole model itself, the agreement between the two sets of maps is considered to be reasonably good.

In an examination of the features in the lone-pair regions, $\Delta \rho_{\mathrm{C} 98}^{\text {multipole }}$ and $\Delta \rho_{\exp }^{\text {multipole }}$ maps were constructed for the planes bisecting the SiOSi angles. As the maps gave little insight into the shape and spatial distribution of the lone-pair features,

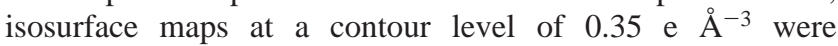
constructed for the five nonequivalent oxide anions (Figure 4). With the exception of isosurface maps for $\mathrm{O} 1$ and the experimental one for $\mathrm{O} 2$, each of the theoretical and experimental maps display a banana-shaped isosurface oriented roughly perpendicular to the plane of SiOSi angle centered at 


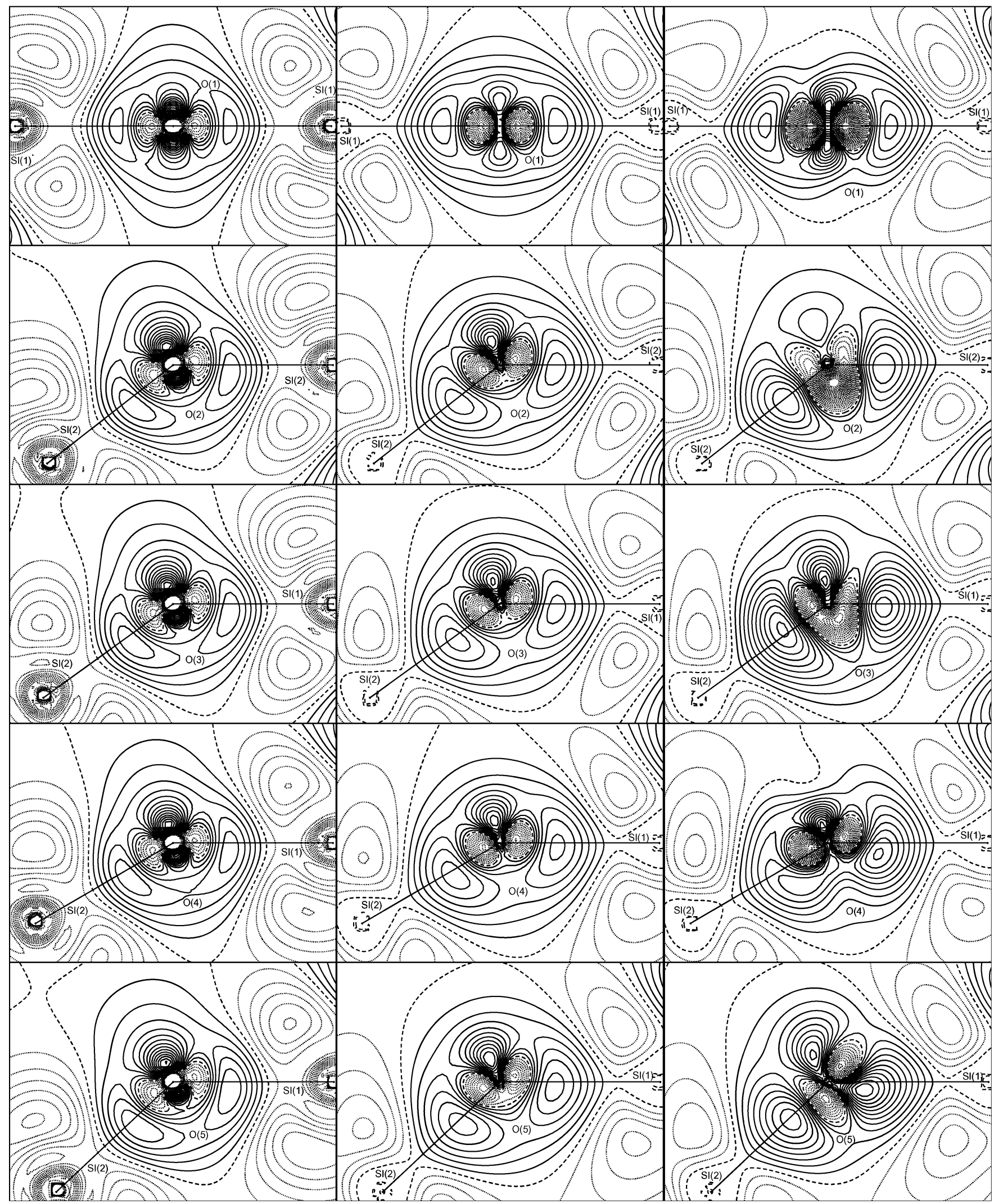

Figure 3. Deformation maps calculated for the planes containing the five nonequivalent $\mathrm{SiOSi}$ angles in coesite. Rows: $\angle \mathrm{Si} 1 \mathrm{O} 1 \mathrm{Si} 1$ (row 1); $\angle \mathrm{Si} 2 \mathrm{O} 2 \mathrm{Si} 2$ (row 2); $\angle \mathrm{Si} 1 \mathrm{O} 3 \mathrm{Si} 2$ (row 3); $\angle \mathrm{Si} 1 \mathrm{O} 4 \mathrm{Si} 2$ (row 4); $\angle \mathrm{Si} 1 \mathrm{O} 5 \mathrm{Si} 2$ (row 5). Columns: column 1, theoretical $\Delta \rho_{\mathrm{C} 98}=\rho_{\mathrm{C} 98}-\rho_{\mathrm{IAM}}$ deformation maps; column 2, theoretical static deformation $\Delta \rho_{\mathrm{C} 98}^{\text {multipole }}=\rho_{\mathrm{C} 98}^{\text {multipole }}-\rho_{\text {IAM }}$ maps; column 3, experimental static $\Delta \rho_{\exp }^{\text {multipole }}=\rho_{\exp }^{\text {multipole }}-\rho_{\text {IAM }}$ deformation maps. Contours are defined in the legend of Figure 1.

$\sim 0.35 \AA$ from the oxygen atom. As expected, the banana-shaped isosurfaces displayed by the theoretical $\Delta \rho_{\mathrm{C} 98}^{\text {multipole }}$ maps are more uniform in size and less distorted than the experimental ones. The experimental lone-pair feature on $\mathrm{O} 2$, rather being banana-shaped, consists of two symmetrically disposed teardropshaped isosurfaces. Upon an increase in the contour level, each banana-shaped isosurface was found to separate into two isosurfaces. The $\Delta \rho_{\exp }^{\text {multipole }}$ and $\Delta \rho_{\mathrm{C} 98}^{\text {multipole }}$ isosurfaces about $\mathrm{O} 1$ 

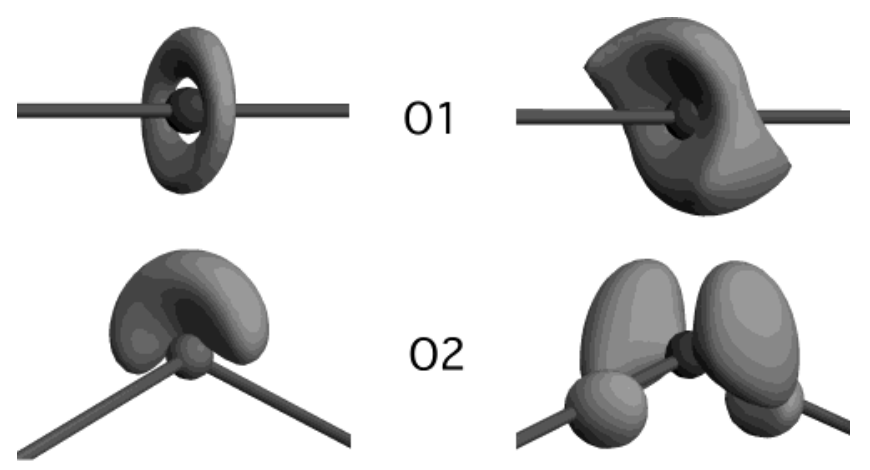

02
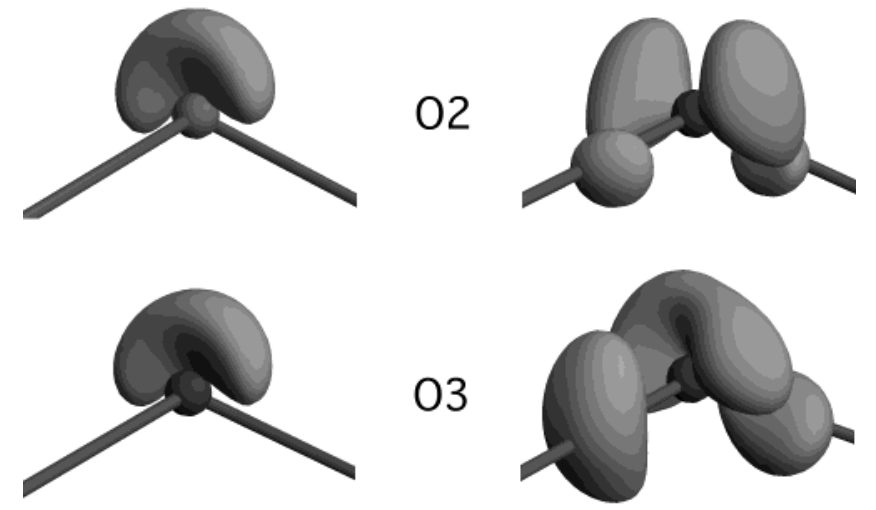

03
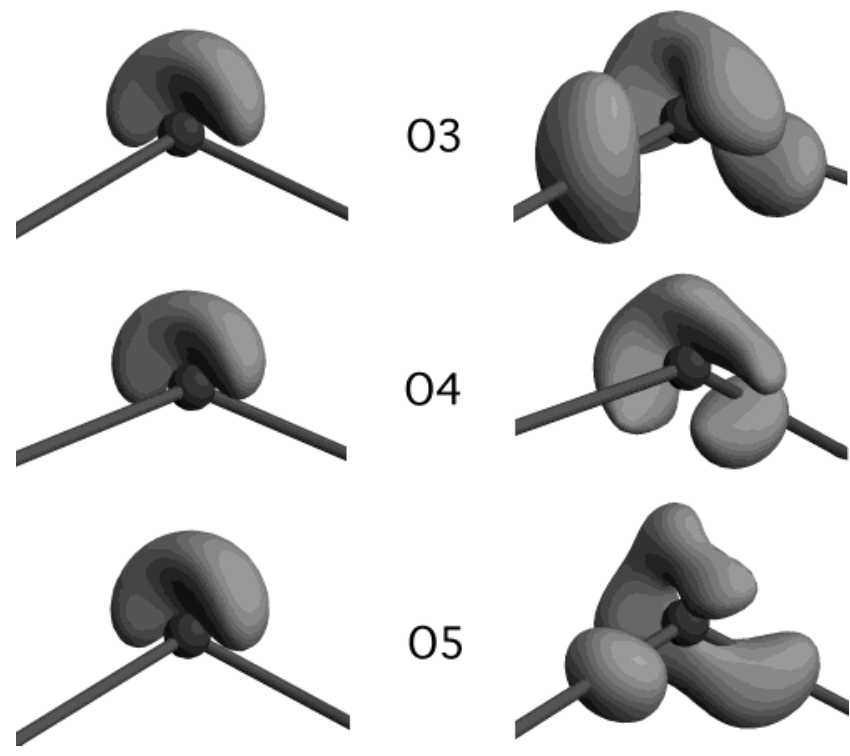

Figure 4. Theoretical $\Delta \rho_{\mathrm{C} 98}^{\text {multipole }}$ (column 1) and experimental $\Delta \rho_{\exp }^{\text {multipole }}$ (column 2 ) ( $\Delta \rho$, isosurfaces displayed for the lone-pair regions of the five nonequivalent oxide anions in coesite $\mathrm{O} 1, \mathrm{O} 2, \mathrm{O} 3$, O4, and O5). The $\mathrm{O} 1$ oxide anion is involved in the straight Si1O1Si1 angle whereas the remaining anions are involved in bent angles. The 0.35 e $\AA^{-3}$ isosurface is displayed.

are both ring torus-shaped, but again the experimental one is more distorted and tilted rather than being perpendicular to the straight SiOSi angle. Teardrop-shaped isosurfaces in $\Delta \rho_{\exp }^{\text {multipole }}$ maps are displayed along the $\mathrm{SiO}$ bond vectors involving $\mathrm{O} 2$, $\mathrm{O} 3$, O4, and $\mathrm{O} 5$ with the features along the vectors merging with those in the lone-pair regions for $\mathrm{O} 4$ and 05 . The $\Delta \rho_{\mathrm{C} 98}^{\text {multipole }}$ maps fail to show any isosurfaces along the $\mathrm{SiO}$ bond vectors inasmuch as the maxima along these vectors are all $\sim 0.33$ e $\AA^{-3}$ or less in height.

The lone-pair features displayed in Figure 4 are strikingly similar to those displayed by ELF and valence electron density isosurface maps calculated in an earlier study of coesite and the $\mathrm{H}_{6} \mathrm{Si}_{2} \mathrm{O}_{7}$ molecule. ${ }^{11}$ Both display banana-shaped isosurfaces in the lone-pair regions of the oxide anions involved in the bent angles. ${ }^{10,11}$ That study also shows that the shape and spatial extent of lone-pair features are both dependent on the size of the SiOSi angle. When the SiOSi angle is $\sim 140^{\circ}$, the ELF maps displayed well-developed banana-shaped isosurfaces oriented perpendicular to the planes of the SiOSi angles, typically located $\sim 0.35 \AA$ from the oxide anion. But, with increasing angle, the isosurfaces became progressively more elongated and completely surround the anion in a quasi-spherically shaped isosurface when the angle is $180^{\circ}$. Isosurface maps of the valence electron density distribution and $\Delta \rho$ for the $\mathrm{H}_{6} \mathrm{Si}_{2} \mathrm{O}_{7}$ molecule likewise display banana-shaped isosurfaces in the lone-pair region when the angle is bent. However, when the angle is straight, they both display a ring torus-shaped isosurface ${ }^{11}$ about the oxygen oriented perpendicular to the SiOSi angle, as observed in Figure 4. A similar feature was reported for the oxide anion involved in the relatively wide $168^{\circ} \mathrm{SiOSi}$ angle in beryl. ${ }^{38}$ The decrease in the ellipticity of the $\mathrm{SiO}$ bond with increasing SiOSi angle described above with the bond becoming circular in cross section is consistent with the ring torus distribution of the $\Delta \rho$ and the valence electron density at $180^{\circ}$.

\section{Laplacian Density Distributions}

A mapping of the $-\nabla^{2} \rho_{\mathrm{C} 98}^{\text {multipole }}$ distribution revealed a single $(3,-3)$ critical point associated with each of the lone-pair regions involved with the anions $(\mathrm{O} 2, \mathrm{O} 3, \mathrm{O} 4$, and $\mathrm{O} 5)$ involved in the bent $\mathrm{SiOSi}$ angles and four distributed at $90^{\circ}$ intervals in a ring torus about the anion, $\mathrm{O} 1$, involved in the straight angle. In contrast, a mapping of $-\nabla^{2} \rho_{\exp }$ multipole revealed a single critical point in the lone-pair region on $\mathrm{O} 4$ and $\mathrm{O} 5$ and two each on $\mathrm{O} 1, \mathrm{O} 2$, and $\mathrm{O} 3$. As observed by MacDougall ${ }^{39}$ and Bader and MacDougall, ${ }^{40}(3,-3)$ critical points in a $-\nabla^{2} \rho$ distribution define regions where the electron density distribution is locally concentrated, regions that are ascribed to domains of bonding and nonbonding electrons. An examination of the $-\nabla^{2} \rho$ maps for the $\mathrm{SiOSi}$ angle of the $\mathrm{H}_{6} \mathrm{Si}_{2} \mathrm{O}_{7}$ molecule has revealed a belt-shaped isosurface, crescent-shaped in cross section, capping the oxide anion and enclosing a single $(3,-3)$ critical point $0.36 \AA$ from the apex of the $\mathrm{SiOSi}$ angle. ${ }^{4}$ The spatial distribution of the nonbonding domain for the molecule ${ }^{11}$ was found to depend on the width of the angle with the isosurface increasing in its extent around the anion and merging as a ring torus about the anion as the angle is increased to $180^{\circ}$. For purposes of comparison, two sets of $-\nabla^{2} \rho$ isosurface maps were generated at the 170 e $\AA^{-5}$ contour level for the $\rho_{\mathrm{C} 98}^{\text {multipole }}$ and

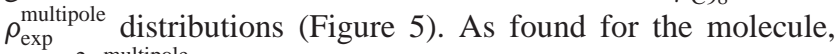
the $\nabla^{2} \rho_{\mathrm{C} 98}^{\text {multipole }}$ isosurface maps display a belt-shaped isosurface centered at the apex of the angle and encircling $\mathrm{O} 2, \mathrm{O} 3, \mathrm{O} 4$, and $\mathrm{O} 5$ about halfway around each anion whereas a ring torusshaped isosurface encircles O1 (Figure 5). The $-\nabla^{2} \rho_{\exp }^{\text {multipole }}$ isosurface maps display similar features with the exception that $\mathrm{O} 2$ has two isosurfaces, as displayed by the $\Delta \rho_{\exp }^{\text {multipole }}$ maps for the anion (Figure 4$)$. Also, unlike the $-\nabla^{2} \rho_{\mathrm{C} 98}^{\text {multipole }}$ maps, the

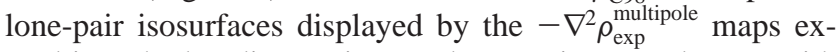
tend into the bonding regions and merge in several cases with the maxima along the $\mathrm{SiO}$ bond vectors as observed for several $\Delta \rho_{\exp }^{\text {multipole }}$ maps.

The $(3,-3)$ local maxima of the lone-pair domains associated with $\mathrm{O} 2, \mathrm{O} 3, \mathrm{O} 4$, and $\mathrm{O} 5$ are systematically $\sim 10$ e $\AA^{-5}$ greater in height than those on $\mathrm{O} 1$ for both the experimental and theoretical distributions (see Figure 5 legend). This evidence shows that the electron density is more locally concentrated in the lone-pair domains of the anions involved in the bent angles and less so in the domain of O1. Accordingly, hydrogen can be expected to preferentially dock in the vicinity of the four more nucleophilic $\mathrm{O} 2, \mathrm{O} 3, \mathrm{O} 4$, and $\mathrm{O} 5$ anions and to avoid less nucleophilic $\mathrm{O} 1$ in a H-bearing coesite crystal, as predicted by Gibbs et al. ${ }^{10,11}$ and established in a concurrent infrared study by Koch-Müller et al. ${ }^{26}$ who found that hydrogen is bonded to four of the five nonequivalent oxide anions, forming a defect $v(\mathrm{OH})_{4}$ group ( $v$ is the vacancy created by a missing $\mathrm{Si}$ atom). The oxide anions comprising the $v(\mathrm{OH})_{4}$ group were established to be $\mathrm{O} 2, \mathrm{O} 3, \mathrm{O} 4$, and $\mathrm{O} 5$. Thus, $\mathrm{H}$ is observed to avoid $\mathrm{O} 1$ and preferentially bonds to anions with domains of greater locally concentrated electron density as predicted. In short, the $-\nabla^{2} \rho_{\exp }^{\text {multipole }}$ and $-\nabla^{2} \rho_{\mathrm{C} 98}^{\text {multipole }}$ isosurface maps generated in 

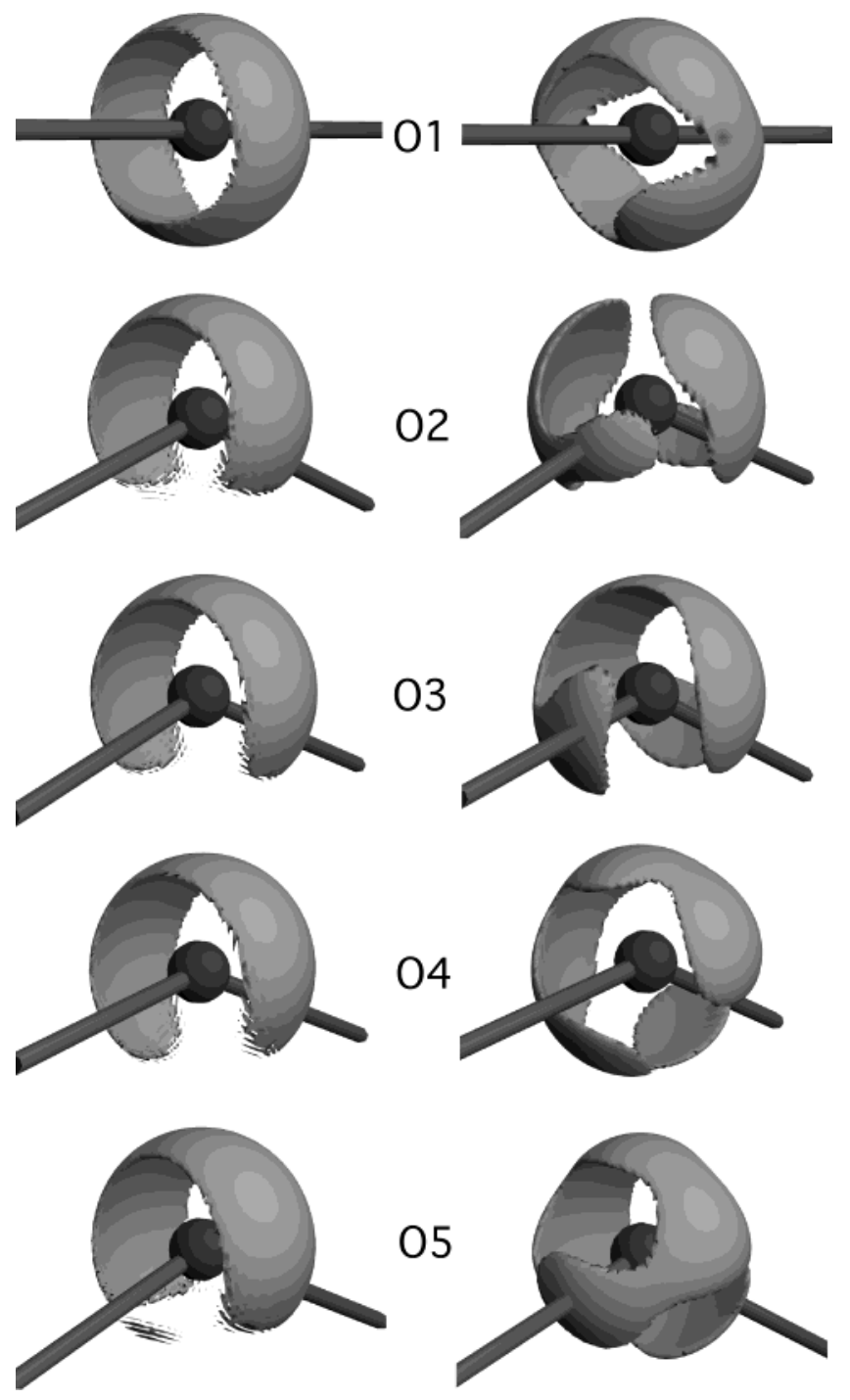

Figure 5. Theoretical $-\nabla^{2} \rho_{\mathrm{C} 98}^{\text {multipole }}$ (column 1) and experimental $-\nabla$ ${ }^{2} \rho_{\exp }^{\text {multipole }}$ (column 2) isosurfaces displayed for the lone-pair regions of the five nonequivalent oxide anions in coesite, $\mathrm{O} 1, \mathrm{O} 2, \mathrm{O} 3, \mathrm{O} 4$ and O5. The 170 e $\AA^{-5}$ isosufaces are displayed. The heights of the (3, -3) maxima associated with the theoretical lone-pair domains on $\mathrm{O} 1$,

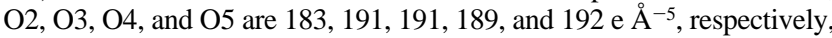
whereas those associated with the experimental lone pairs are 190, 220, 209,210 , and $213 \mathrm{e}^{-5}$, respectively.

this study provide an experimental and theoretical basis for the strategy used to determine the positions of hydrogen in H-bearing coesite, quartz, and stishovite. ${ }^{11,12}$

\section{Bond Critical Point Properties}

The bond critical point properties determined for the $\rho_{\exp }^{\text {multipole }}$ distribution are given in Table 3 . Unlike the experimental properties determined earlier, ${ }^{17}$ they show a smaller range of values similar to those calculated for the $\mathrm{H}_{12} \mathrm{Si}_{5} \mathrm{O}_{16}$ moieties of the coesite structure ${ }^{9}$ and the structure itself. ${ }^{18}$ The experimental values for $\lambda_{3}$ and $\nabla^{2} \rho$ display a weak negative correlation with $R(\mathrm{SiO})$ whereas $\rho\left(r_{\mathrm{c}}\right)$ and $\left|\lambda_{1,2}\right|=1 / 2\left|\lambda_{1}+\lambda_{2}\right|$ are both independent of the bond length as found earlier. ${ }^{17}$ On the other hand, a well-developed correlation is displayed between the bonded radius of the oxide anion, $r_{\mathrm{b}}(\mathrm{O})$, and $R(\mathrm{SiO})$. In addition, properties were also generated for $\rho_{\mathrm{C} 98}^{\text {multipole }}$; these together with those generated for the model structure of coesite ${ }^{18}$ are also given in Table 3. Considering the small range of $\mathrm{SiO}$ bond lengths and the inflexibility of the radial functions used to generate $\rho_{\exp }^{\text {multipole }}$, the agreement between the theoretical and the experimental properties is considered to be good. It is noteworthy that in each of these cases the theoretical bond lengths correlate with $\rho\left(r_{\mathrm{c}}\right),\left|\lambda_{1,2}\right|, \lambda_{3}$, and $\nabla^{2} \rho\left(r_{\mathrm{c}}\right)$, each increasing in value with decreasing $R(\mathrm{SiO})$.

As observed earlier, stishovite ${ }^{23}$ is the only other silica polymorph for which the bcp properties have been experimentally determined. The combined experimental properties for these two silica polymorphs are compared in Figure 6 with those calculated for a relatively large number of silicate crystals. ${ }^{4,12}$ The experimental $R(\mathrm{SiO})$ vs $\rho\left(r_{\mathrm{c}}\right)$ values for the two polymorphs fall, for the most part, within the scatter of the trend displayed by the silicate data set (Figure 6a). As such, the trend generated for the combined experimental data follows that calculated for the silicates with the shorter bonds involving the larger $\rho\left(r_{\mathrm{c}}\right)$ values. The experimental $R(\mathrm{SiO})$ vs $\left|\lambda_{1,2}\right|$ data set parallels that

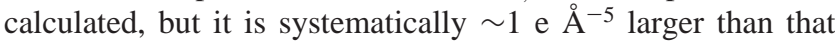
calculated (Figure 6b). In addition, the experimental $R(\mathrm{SiO})$ vs $\lambda_{3}$ data set not only parallels but falls close to the silicate trend (Figure 6c). The increase in $\lambda_{3}$ with decreasing bond length reflects an increase in the force constant of the $\mathrm{SiO}$ bond, rendering the shorter bonds more resistant to change by compaction. ${ }^{8}$ The $R(\mathrm{SiO})$ vs $\nabla^{2} \rho\left(r_{\mathrm{c}}\right)$ data set also parallels the silicate trend, but on average, they tend to be somewhat smaller overall (Figure $6 \mathrm{~d}$ ). The correlations between $R(\mathrm{SiO})$ and $r_{\mathrm{b}^{-}}$ (O) are not only well-developed for both coesite and stishovite, but they agree very well with that defined by the silicates (Figure $6 \mathrm{e})$. Given the relatively wide range of bond lengths, $\sim 0.25 \AA$,

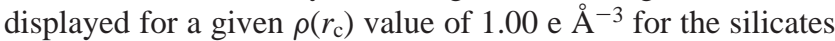
(Figure 6a), perhaps it is not surprising that the bond lengths for coesite, with a range of $0.026 \AA$, fail to correlate with $\rho\left(r_{\mathrm{c}}\right)$. On the other hand, given the small scatter of data for the linear $R(\mathrm{SiO})$ vs $r_{\mathrm{b}}(\mathrm{O})$ trend displayed by the silicates, it may not be surprising that the observed $R(\mathrm{SiO})$ vs $r_{\mathrm{b}}(\mathrm{O})$ correlation is welldeveloped. Overall, however, the agreement displayed in Figure 6 is evidence that computational chemistry and physics have both advanced to the stage where they do a reliable job in reproducing the electronic structure of the $\mathrm{SiO}$ bond. It also reflects very well on the quality of the current experimental data and the multipole model used in this study. Also, the good agreement between the experimental bcp properties and those calculated for the $\mathrm{H}_{12} \mathrm{Si}_{5} \mathrm{O}_{16}$ moieties is further evidence that the experimental electron density distribution displayed by coesite is strikingly similar to that displayed by representative molecules.

As the observed $\mathrm{SiO}$ bond lengths decrease for the large silicate data set from 1.86 to $1.57 \AA, \nabla^{2} \rho\left(r_{\mathrm{c}}\right)$ increases in value from $\sim 7$ to $\sim 27$ e $\AA^{-5}$ with a concomitant increase in $\rho\left(r_{\mathrm{c}}\right)$

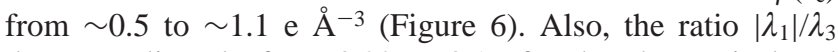
decreases linearly from 0.22 to 0.17 for the change in bond length. As observed above, the large positive value for $\nabla^{2} \rho\left(r_{\mathrm{c}}\right)$ calculated for these bonds is typical of a closed-shell ionic interaction, particularly because $\left|\lambda_{1}\right| / \lambda_{3}$ is less than 0.25 . However, the inherent nature of the electron density distributions of the $\mathrm{Si}$ and $\mathrm{O}$ atoms in the internuclear region of the interaction virtually guarantees that as $R(\mathrm{SiO})$ decreases, $\lambda_{3}$ must necessarily increase in value, ${ }^{24,41}$ resulting in a concomitant increase in the value for $\nabla^{2} \rho\left(r_{\mathrm{c}}\right)$.

As observed by Bader, ${ }^{8}$ the formation of a $(3,-1)$ critical point in the electron density distribution between a pair of bonded atoms such as $\mathrm{Si}$ and $\mathrm{O}$ indicates that the electron density is localized in the binding region between the nuclei with $\rho$ reaching a local maximum value along the bond path. Further, 

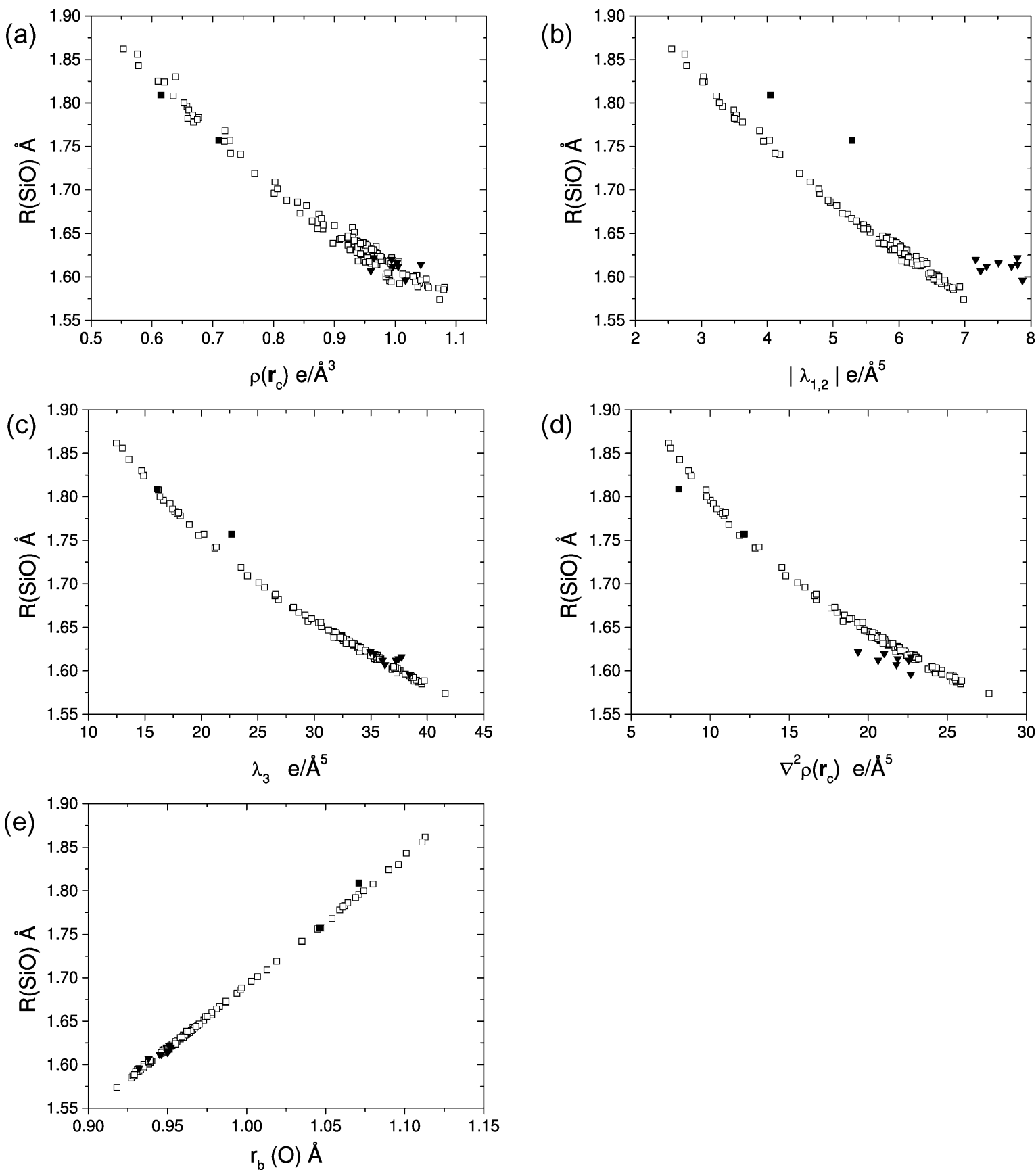

Figure 6. Observed $\mathrm{SiO}$ bond lengths, $R(\mathrm{SiO})$, plotted against (a) $\rho\left(r_{\mathrm{c}}\right)$, (b) $\left|\lambda_{1,2}\right|=1 / 2\left|\left(\lambda_{1}+\lambda_{2}\right)\right|$, (c) $\lambda_{3}$, (d) $\nabla^{2} \rho\left(r_{\mathrm{c}}\right)$, and (e) $r_{\mathrm{b}}(\mathrm{O})$, where $\rho\left(r_{\mathrm{c}}\right)$ is the value of the electron density at the bcp, $r_{\mathrm{c}},\left|\lambda_{1}\right|$, and $\left|\lambda_{2}\right|$ are the curvatures of $\rho\left(r_{\mathrm{c}}\right)$ measured perpendicular to the bond path, $\lambda_{3}$ is the curvature of $\rho\left(r_{\mathrm{c}}\right)$ measured parallel to the bond path, and $r_{\mathrm{b}}(\mathrm{O})$ is the bonded radius of the oxide anion bonded to Si. The silicate crystal bcp properties ${ }^{4}$ together with those for other silicates ${ }^{12}$ are plotted as open squares, the coesite experimental bcp properties are plotted as solid triangles, and the stishovite experimental bcp properties ${ }^{23}$ are plotted as solid squares.

when $\nabla^{2} \rho\left(r_{\mathrm{c}}\right)$ is negative, the electron density is locally concentrated at the bcp, which in turn is asserted to exert a net attractive force on the nuclei of the bonded atoms, all other things being equal, the larger the magnitude of $-\nabla^{2} \rho\left(r_{\mathrm{c}}\right)$, the greater the force and the shorter the bond length. ${ }^{8}$ However, as observed above, the separation between $\mathrm{Si}$ and $\mathrm{O}$ decreases as $\nabla^{2} \rho\left(r_{\mathrm{c}}\right)$ increases in value (Figure 6d). As $\nabla^{2} \rho\left(r_{\mathrm{c}}\right)$ is positive, the electron density is locally depleted at the $r_{\mathrm{c}}$ and in its immediate vicinity, ${ }^{41}$ indicating a reduction of the net attractive force between $\mathrm{Si}$ and $\mathrm{O}$. Under these conditions, the $\mathrm{SiO}$ bond may be expected to lengthen as the electron density is progressively locally depleted in the binding region. ${ }^{8}$ However, concomitant with the increase of $\nabla^{2} \rho\left(r_{\mathrm{c}}\right)$, electron density is localized in the binding region between $\mathrm{Si}$ and $\mathrm{O}$ as the value of $\rho\left(r_{\mathrm{c}}\right)$ increases in a regular way (Figure 6a,d). This evidence suggests that it is the value of $\rho\left(r_{\mathrm{c}}\right)$ that plays the dominant role in governing the length of the $\mathrm{SiO}$ bond, not the local depletion of $\rho\left(r_{\mathrm{c}}\right)$ in the binding region. It also suggests that $\rho\left(r_{\mathrm{c}}\right)$ can be used as a measure of bond type, the greater its value, the more covalent a bonded interaction. ${ }^{4,24}$ Indeed, a plot of the average value of $\rho\left(r_{\mathrm{c}}\right),\left\langle\rho\left(r_{\mathrm{c}}\right)\right\rangle$ for a given MO bond vs the spectroscopic electronegativity, $\chi_{\mathrm{spec}}$, for first and second row $\mathrm{M}$ metal atoms ${ }^{42}$ bonded to an oxide anion shows that $\left\langle\rho\left(r_{\mathrm{c}}\right)\right\rangle$ increases in a regular way with $\chi_{\text {spec }}{ }^{4}$ If traditional arguments hold between electronegativity and bond type, then the character of a bonded interaction can be directly related to $\left\langle\rho\left(r_{\mathrm{c}}\right)\right\rangle$ : the greater its value, the more covalent the bonded interaction. 
In the case of the $\mathrm{SiO}$ bonded interactions in coesite, the observed $\left\langle\rho\left(r_{\mathrm{c}}\right)\right\rangle$ value, $1.0 \mathrm{e} \AA^{-3}$, indicates that the bond is more covalent, for example, than $\mathrm{KO}, \mathrm{NaO}, \mathrm{LiO}, \mathrm{CaO}, \mathrm{MgO}, \mathrm{BeO}$, and $\mathrm{AlO}$ bonds, given that these interactions display smaller

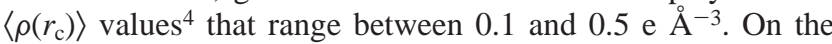
other hand, the bond is indicated to be more ionic than PO, $\mathrm{SO}$, and $\mathrm{CO}$ bonded interactions given that these bonds display

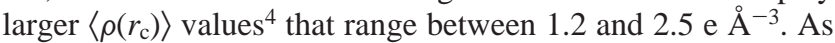
observed above ${ }^{17}$ and as concluded more than 60 years ago, ${ }^{43}$ these results suggest that the $\mathrm{SiO}$ bond is intermediate in character between these two sets of bonded interactions rather than qualifying as a closed-shell ionic interaction, ${ }^{8,19}$ consisting of nearly fully charged and spherical $\mathrm{Si}^{4+}$ and $\mathrm{O}^{2-}$ ions. ${ }^{44}$

\section{Summary and Comments on Hydrogen Positions in Stishovite}

The observed $\Delta \rho\left(r_{\mathrm{c}}\right)$ and $-\nabla^{2} \rho\left(r_{\mathrm{c}}\right)$ maps reported in this study display a localization and a local concentration of electron density in both the bonding and nonbonding regions of coesite, compelling evidence that the $\mathrm{SiO}$ bonded interaction is intermediate in character between closed-shell ionic and shared covalent. ${ }^{14,15} \mathrm{In}$ addition, the preference of $\mathrm{H}$ for the oxide anions with well-developed lone pairs is further evidence that the anions involved in bent angles are not spherical like an $\mathrm{O}^{2-}$ anion but possess lone-pair features that are typical of covalent interactions. On the basis of electronegativity considerations, Kirfel et al. ${ }^{23}$ have concluded that the $\mathrm{SiO}$ bond in stishovite is somewhat more ionic than a bond of intermediate character for silica polymorphs such as coesite and quartz. It is noteworthy that static deformation maps for stishovite show well-defined but smaller maxima along the $\mathrm{SiO}$ bonds and in the lone-pair region of the oxygen atom..$^{23,45,46}$ Like coesite, the maximum in the lone-pair region has been shown to be a favorable site for docking $\mathrm{H}$ in $\mathrm{H}$-bearing stishovite. ${ }^{10-12}$ The location of this site has been substantiated by first-principle calculations for $\mathrm{H}$ and $\mathrm{Al}$ doped stishovite model structures, ${ }^{47}$ where the $\mathrm{OH}$ vector was found to be perpendicular to [001], as observed in a study of the infared spectra. ${ }^{27}$ Clearly, the presence of the bonded and nonbonded features displayed in the observed electron density distribution indicates that the $\mathrm{SiO}$ bond in stishovite likewise has covalent character ${ }^{23}$ but to a lesser extent than that for silica polymorphs with four-coordinate $\mathrm{Si}$. On the other hand, arguments based on the bond critical point properties for the bonded interactions in both coesite and stishovite, and in particular the large values for $-\nabla^{2} \rho\left(r_{\mathrm{c}}\right)$ displayed for coesite, indicate that the bond is closed-shell ionic, ${ }^{19}$ a conclusion that is difficult to accept for a second row atom like Si given the bonding and nonbonding features displayed in the ELF, $\Delta \rho$, and $\nabla^{2} \rho$ maps for $\mathrm{SiO}$ bonded interactions.

Finally, given the problems encountered in collecting and modeling the experimental data, it appears that the theoretical electron density distribution generated for coesite is more accurate and meaningful than that determined with the experimental data. The good agreement between the observed bond lengths and angles ${ }^{4}$ and the bond critical point properties ${ }^{24}$ and those calculated for representative moieties ${ }^{9}$ lend support to the argument that the $\mathrm{SiO}$ bonded interactions in coesite behave as if short ranged and molecular in nature ${ }^{5}$ rather than long ranged as in an ionic crystal consisting of nearly fully charged $\mathrm{Si}^{4+}$ and $\mathrm{O}^{2-}$ ions. ${ }^{14,44}$

Acknowledgment. It is a pleasure to thank the National Science Foundation for generously supporting this study with Grant EAR-9627458 awarded to G.V.G. and Monte B. Boisen,
Jr. This study was initiated during the spring of 2002 while G.V.G. was a Visiting NSF Scholar at The University of Arizona where the coesite intensity data were collected. The multipole modeling of the electron density distribution was completed and the paper was written while G.V.G. was a NSF Visiting Scholar in the Chemistry Department at the University of New England, Armidale, Australia. The faculty (M.A.S. and Geoff Ritchie, in particular) and Postdoctoral Fellow Joshua McKinnon and Ph.D. students Xiaoxiong Meng and Andrew Whitten are thanked for their kind hospitality and for making the visit a stimulating and very worthwhile experience. The Faculty of the Sciences at the University of New England is also thanked for awarding G.V.G. a Visiting Distinguished Professor Scholarship. We thank an unknown reviewer for a careful reading of the manuscript and for pointing out a discrepancy in one of the figures.

\section{References and Notes}

(1) Heaney C. T.; Prewitt C. T.; Gibbs G. V. Silica; Reviews in Mineralogy, Vol. 29; Mineralogical Society of America: Washington, DC 1994; p 331.

(2) Teter D. M.; Gibbs G. V.; Boisen M. B.; Allan D. C.; Teter, M. P. Phys. Rev. B 1995, 52, 8064.

(3) Geisinger K. L.; Gibbs G. V. Phys. Chem. Miner. 1981, 7, 204

(4) Gibbs G. V.; Boisen M. B.; Beverly L. L.; Rosso K. M. In A Computational Quantum Chemical Study of the Bonded Interactions in Earth Materials and Structurally and Chemically Related Materials. Cygan, R. T., Kubicki, J. D., Eds.; Molecular modeling theory: Applications in the Geosciences. Reviews in Mineralogy and Geochemistry, Vol. 42; Mineralogical Society of America: Washinton, DC, 2001; p 335.

(5) Gibbs G. V. Am. Mineral. 1982, 67, 421.

(6) Geisinger K. L.; Gibbs G. V.; Navrotsky, A. Phys. Chem. Miner. 1985, 11, 266.

(7) Gibbs G. V.; Downs J. W.; Boisen M. B., Jr. In The Elusive SiO Bond; Heaney, P. J.; Prewitt, C. T., Gibbs G. V., Eds.; SILICA, Reviews in Mineralogy, Vol. 29; Mineralogical Society of America: Washinton, DC, 1994; p 331.

(8) Bader R. F. W. Atoms in Molecules; Oxford Science Publications: Oxford, U.K. ,1990; p 438.

(9) Rosso K. M.; Gibbs G. V.; Boisen M. B. Phys. Chem. Miner. 1999, 26,264

(10) Gibbs G. V.; Cox D. F.; Crawford T. D.; Boisen M. B., Jr.; Lim M. Phys. Chem. Miner. 2002, 29, 307.

(11) Gibbs G. V.; Cox D. F.; Boisen M. B., Jr.; Downs R. T.; Ross N. L. Phys. Chem. Miner. 2003, 30, 305.

(12) Ross N. L.; Gibbs G. V.; Rosso K. M. Am. Mineral. 2003, 81, 1452 .

(13) Geisinger K. L.; Spackman M. A.; Gibbs G. V. J. Phys. Chem. 1987, 91, 3237

(14) Coppens P. X-ray Charge Densities and Chemical Bonding; Oxford Science Publications: Oxford, U.K., 1997; p 358.

(15) Tsirelson V. G.; Evdokimova O. A.; Belokoneva E. L.; Urusov V. S. Phys. Chem. Miner. 1990, 17, 275.

(16) Cohen R. E. In First-Principle Theory of Crystalline $\mathrm{SiO}_{2}$; Heaney, P. J.; Prewitt, C. T., Gibbs G. V., Eds.; SILICA, Reviews in Mineralogy, Vol. 29; Mineralogical Society of America: Washinton, DC, 1994; p 369.

(17) Downs, J. W. J. Phys. Chem. 1995, 99, 6849.

(18) Gibbs G. V.; Boisen, M. B., Jr.: Rosso K. M.; Teter D. M. Bukowinski M. S. T. J. Phys. Chem. 2000, 104, 10534.

(19) Bader R. F. W.; Essën H. J. Chem. Phys. 1984, 80, 1943.

(20) Downs, J. W.; Swope, R. J. J. Phys. Chem. 1992, 96, 4834.

(21) Brown A. S.; Spackman M. A. Acta Crystallogr. 1991, A47, 21.

(22) Volkov A.; Coppens P. Acta Crystallogr. 2001, A57, 395.

(23) Kirfel A.; Krane H. G.; Blaha P.; Scwartz K.; Lippmann T. Acta Crystallogr. 2001, A57, 663.

(24) Gibbs G. V.; Boisen, M. B., Jr.; Hill F. C.; Tamada O.; Downs R. T. Phys. Chem. Miner. 1998, 25, 574.

(25) Gibbs G. V.; Prewitt C. T.; Baldwin K. J. Zeits. Kristallogr. 1977, $145,108$.

(26) Koch-Müller M.; Fei Y.; Hauri E.; Liu Z. Phys. Chem. Miner. 2001, $28,693$.

(27) Pawley A. R.; McMillian P. F.; Holloway J. R. Science 1993, 261, 1024

(28) Bruker. SAINT Reference Manual Version 5; Bruker AXC Inc.: Madison WI, 1997.

(29) Blessing R. H. Cryst. Rev. 1987, 1, 3

(30) Sheldrick G. M. SADABS; Siemans Area Detector Absorption Software; University of Gottingen: Gottingen, Germany, 1996. 
(31) Saunders V. R.; Dovsi R.; Roetti C.; Causa M.; Harrison N. M.; Orlando R.; Zicovich-Wilson C. M. CRYSTAL98 User's Manual; University of Torino: Torino, 1998.

(32) Thakkar A. J.; Koga T.; Saito M.; Hoffmeyer R. E. Int. J. Quantum Chem. 1993, 27, 344

(33) Koga T.; Saito M.; Hoffmeyer R. E.; Thakkar A. J. J. Mol. Struct. 1994, 306, 249 .

(34) Hirshfeld F. L. Isr. J. Chem. 1977, 16, 226.

(35) Stewart R. F.; Spackman M. A.; Flensburg C. VALRAY Users Manual; Carnegie Mellon University \& University of Copenhagen, 2000.

(36) Kuntzinger S.; Ghermani N. R.; Dusausoy Y.; Lecomte C. Acto Crystallogr. 1998, 54, 819

(37) Downs R. T. Analysis of Harmonic Displacement Factors; Hightemperature and high-pressure Crystal Chemistry; Reviews in Mineralogy and Geochemistry, Vol. 41; Mineralogical Society of America: Washinton, DC, 2000; p 61
(38) Prencipe M. Phys. Chem. Miner. 2002, 29, 552.

(39) MacDougall P. J. The Laplacian of the Electron Charge Distribution. Ph.D. Thesis, McMaster University, 1989; p 128.

(40) Bader R. F. W.; MacDougall P. J. J. Am. Chem. Soc. 1985, 107, 6788 .

(41) Gibbs G. V.; Hill F. C.; Boisen, M. B., Jr. Phys. Chem. Miner. 1997, 24, 167

(42) Allen L. C. J. Am. Chem. Soc. 1989, 111, 9003.

(43) Pauling, L. The Nature of the Chemical Bond, 2nd ed.; Cornell University Press: Ithaca, NY, 1939; p 326.

(44) Gillespie R.; Johnson S. A. Inorg. Chem. 1997, 36, 3031.

(45) Hill R. J.; Newton M. D.; Gibbs G. V. J. Solid State Chem. 1997, 24,582 .

(46) Spackman M. A.; Hill R. J.; Gibbs G. V. Phys. Chem. Miner. 1987, 14,139 .

(47) Gibbs G. V.; D. F. Cox; Ross N. L. Phys. Chem. Miner., in press. 